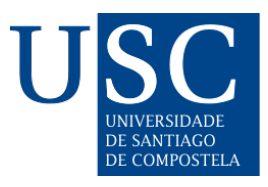

\title{
Los amnésicos: Historia de una familia europea
}

Diego de La Calle y Díaz

Máster en Corporate y Práctica de la abogacía (ISDE y UDIMA), España

“Todos nosotros, culpables o no, jóvenes o viejos, debemos aceptar el pasado. Todos nos hemos visto afectados por sus consecuencias y somos responsables. Los alemanes debemos mirar la verdad directamente a los ojos, sin adornos y sin distorsión [...]. No puede haber reconciliación sin memoria". Era 8 de mayo de 1985, Europa occidental celebraba el 40 aniversario del fin de la Guerra y quien pronunciaba estas palabras era Richard Von Weizsäcker, presidente de la República Federal, antiguo oficial de la Wehrmacht cuyo padre había sido condenado en Nuremberg por participar activamente en la deportación de judíos a los campos de exterminio. Su discurso, que insistía en identificar aquella efeméride como la de la liberación de Alemania, se tradujo en 13 idiomas, fue reproducido enteramente en las páginas del New York Times y la jefatura del estado recibió más de 60000 cartas de ciudadanos alemanes. Era la primera vez que un dirigente alemán de primer orden identificaba el fin de la guerra como una liberación y no como una derrota trágica. A su vez, mientras reconocía la complicidad con el nazismo de la sociedad alemana, el presidente insistía en que las generaciones futuras no podían seguir cargando con la responsabilidad de unos crímenes que no cometieron. Con este discurso se inauguraba una nueva forma de aproximación a un pasado muy presente, muy reciente, profundamente traumático y que exigía no olvidar nunca. Así se afirmaba desde el ámbito institucional, pero ¿qué sucedía en la cabeza de los alemanes, en el ámbito doméstico? ¿cómo enfrentaba cada familia su particular memoria histórica? ¿qué relación establecían con el pasado los hijos de aquellos que se beneficiaron, directa o indirectamente, de las políticas nazis? ¿o las familias que no se vieron en ningún momento atacadas por el régimen nazi y pudieron desarrollar sus vidas mientras sus propios vecinos eran arrancados de sus casas y exterminados? En una original obra, la periodista franco-alemana Geraldine Schwarz, reconvertida en historiadora y especializada en los archivos del Servicio Federal de Inteligencia de la RFA (el BND), desarrolla un trabajo excepcional vinculado a su propia historia familiar. Los amnésicos, publicado en castellano por Tusquets Editores y que cuenta con un epílogo firmado por el historiador y catedrático emérito José Álvarez Junco, recibió el Premio Libro Europeo 2018. El escrito comienza relatando cómo, casi por casualidad, la autora descubre que, en 1938, su abuelo compró, a bajo precio, una empresa a unos judíos que poco después serían deportados y exterminados en Auschwitz. Esta primera revelación la impulsa a interesarse por el posicionamiento que tuvieron los miembros de su familia con respecto al régimen nazi. Beneficiados por las políticas raciales de la Alemania de los 30, muchos de aquellos "que seguían la corriente" accedieron a puestos anteriormente ocupados por judíos, otros a sus empresas, otros vieron sus ingresos aumentar como consecuencia de los boicots a sus competidores y otros se mudaron a lujosos apartamentos o amueblaron sus hogares a muy bajo 
precio. El texto, que desarrolla la metahistoria del proceso de averiguación, le lleva a desgranar la recepción del presente y del pasado en una familia de mitläufer, simpatizantes pasivos, contagiados por la euforia de los aparentes éxitos del nacionalsocialismo, miembros nominales del partido que se limitaban a asistir a las reuniones obligatorias (y a pagar la cuota), nunca directamente vinculados, pero fieles y silenciosamente agradecidos que con su aquiescencia facilitaron el trabajo de las autoridades. Schwarz nos habla de los elocuentes silencios siempre presentes en cualquier familia, de las fidelidades que sobrevivieron al público reconocimiento de la barbarie nazi y de la necesidad de olvidar, en algunos casos, para poder negar una culpa que se hace evidente en caso contrario. Algunas de las personas puestas como ejemplo parecen ampararse en un concepto desproporcionado del "estado de necesidad" que les obligaba a beneficiarse de la oportunidad, otros, por el contrario, lo hacen en el determinismo, afirmando que, de cualquier forma, su contribución, oposición, complicidad, colaboración o indiferencia, en nada hubiera cambiado el desarrollo último de los acontecimientos. Si Karl, su abuelo, no hubiera comprado la empresa, cualquier otro lo hubiera hecho, quizás incluso a un precio más bajo, argüía él mismo cuando los herederos de los antiguos dueños trataron de obtener una legítima compensación. Los derroteros psicológicos que siguieron los testigos del nazismo -el cómo muchos de ellos enfrentaron la cruda excepcionalidad del exterminio como si de una más de las complicadas realidades de la vida se tratara- componen el núcleo fundamental del trabajo. La autora extrae así una serie de conclusiones relacionadas con la "Vergangenheitsbewältigungl", la "gestión del pasado", en palabras de Helmut König. Schwarz expone como, gracias a una disociación del concepto de responsabilidad, los crímenes del genocidio son integrados en el conjunto de víctimas de la guerra, facilitando una suerte de amnesia colectiva. El libro es un retablo de antiguas simpatías y de deudas intelectuales y materiales nunca saldadas, de confusiones históricas comunes e individuales, de encuentros y desencuentros entre la historia privada y la pública, la conocida y la desconocida, la familiar, la social y la política. Los capítulos se van jalonando a la par que la profundización histórico-psicológica avanza, enfrentando, como se ha referido con anterioridad, autora e investigación. La obra recoge, en primer lugar, los frutos de la Alltagsgeschichte, la historia de lo cotidiano, de lo doméstico -nacida en la propia Alemania a comienzos de los 80, tan interesada en las prácticas del día a día como en la historia de las mentalidades y el epistemológicamente problemático "verstehen" (comprender)-. De la segunda deuda historiográfica del trabajo son beneficiarias las corrientes pro-narrativistas de la historia: desde una escritura que no reniega del "yo" historiador, sino que lo explicita, la autora se expone abiertamente en el texto, enfrentándose a sus propios descubrimientos. Cabría, a su vez, identificar este trabajo dentro la relativamente reciente pero fecunda tradición del "relato real" de la que sobran ejemplos en España -, un tipo de escritura que se apoya en formas literarias para tratar el objeto histórico desde una mezcla entre ensayo, reportaje y libro de historia, y que sitúa el propio proceso de averiguación y seguimiento de indicios en el centro. El tema del trabajo se inscribe en el llamado boom memorialístico (Winter, 1999) que nació, precisamente, para tratar de estudiar el "siglo del testigo" (Wierviorka, 1998). Por su parte, el ir y venir entre lo particular y lo general, un desafío fundamental de la escritura de la historia, es gestionado con elegancia por una autora acostumbrada a trabajar bajo el báculo de la lógica de la seducción que tanto castiga en ocasiones a esta disciplina. El trabajo es constantemente enriquecido con una aproximación facilitada por la particular posición de la escritora: ejemplos de familiares y vecinos que hablan de las infinitas vicisitudes que enfrentaron los supervivientes de la ciudad de Mannheim, en el Estado de Baden-Wurtemberg, donde se asentaba la familia, y muestran aquel contexto en su complejísima realidad. Su historia familiar también posee una vertiente francesa, en lo que podríamos considerar 
un ejercicio de la novedosa microhistoria global, que expone una misma realidad circulatoria ${ }^{1}$. Al igual que los alemanes, Francia (así como Italia o Austria) también parece tener algo que enfrentar en su pasado (Paxton, 1973). Los conflictos emergentes entre las generaciones pre y post Segunda Guerra Mundial inauguran una reflexión sobre la impermeabilidad de la memoria. Schwarz describe como, dejando atrás el silencio sepulcral que caracterizó los quince años posteriores a la derrota del nazismo, a finales de la década de los cincuenta, el gobierno se ve obligado a reaccionar ante el auge del antisemitismo, a la par que trata de cerrar en falso una desnazificación que ponía nerviosos a muchos -facilitando la impunidad-. A partir de la década siguiente, el nazismo dejaría de considerarse como una cosa del "pasado", y se reconocería su impertérrita presencia. Este proceso alcanza su cenit a finales de los 60, en el contexto de las movilizaciones estudiantiles, cuando una generación de jóvenes nacidos durante o inmediatamente después de la guerra se atreve, definitivamente, a preguntar a sus padres por su rol en aquellos años. En los años 80, con el retorno de los democratacristianos al poder, se logra una cierta relativización que enfrenta la culpabilidad colectiva a nuevas perspectivas -políticas, pero también historiográficas, que provocaron la Disputa de los historiadores, protagonizada por Habermas y Nolte-. Del debate público y académico saldrá encumbrado el discurso que abre esta reseña pero que ni mucho menos zanja definitivamente la cuestión. En conclusión, la aproximación microhistórica, una vez más, permite identificar corrientes, flujos, y perspectivas ignoradas por gran parte de la historiografía, que nunca ha terminado de alejarse del todo de las grandes cuestiones de la interpretación (del nazismo, del comunismo, del totalitarismo, ...) para volcarse en el estudio de las realidades locales cuando de encontrar una verdadera propuesta epistemológica para el estudio de la subalternidad se trata. La recepción de la información acerca de los programas de exterminio, los escandalosos fallos e incoherencias de los procesos de desnazificación, y, sobre todo, la evolución de la memoria histórica en Alemania en el ámbito público y en el privado, van definiendo el retrato de una Alemania en la que el conocimiento de los crímenes nazis depende del año de nacimiento o de la zona de ocupación en la que una persona recibió su educación más elemental, a la vista del silencio familiar y mediático - que no fue roto, en el segundo de los casos, hasta finales del siglo XX-. Esta obra supone, por lo tanto, una novedosa aproximación a la banalidad del mal. Desde una perspectiva familiar y local se descubre toda una serie de pulsiones ocultas, silenciosas y muy resilientes a los cambios políticos, pero absolutamente relevantes para la comprensión, entre otros, del concepto de totalitarismo, poniendo de relieve la importancia del papel del estado en la conformación de la memoria colectiva.

\section{Información Adicional:}

Título: Los amnésicos: Historia de una familia europea

Autor: Gérandine Schwarz

Editorial: Tusquets Editores

Año de edición: 2019 Reedición [2017]

Páginas: 400

ISBN: 978-84-1324-765-6 


\section{REFERENCIAS BIBLIOGRÁFICAS}

CROWNSHAW, RICHARD; KILBY, JANE; ROWLAND, ANTONY (2010). The future of memory, Oxford, Berghahn Books.

DOSSE, FRANÇOIS ; OFFENSTADT, NICOLAS ; DELACROIX, CHRISTIAN ; GARCIA, PATRICK (dir.) (2010). Historiographies (Tome II). Concepts et débats, Paris, Gallimard, Coll. « Folio ».

JABLONKA, IVAN (2014). L'Histoire est une littérature contemporaine. Manifeste pour les sciences sociales, Paris, Seuil, coll. « Librairie du XXIe siècle ».

KOHLSTRUCK, MICHAEL (1998). Vergangenheitsbewältigung am Ende des zwanzigsten Jahrhunderts, Ed. Wöll, Andreas (Hrsg.).

PAXTON, ROBERT (1973 [1974]). La Francia de Vichy, Barcelona, Editorial Noguer.

WIEVIORKA, ANNETTE (1998 [2013]). L'ère du témoin, Paris, Editorial Hachette.

WINTER, JAY (1999). War and Remembrance in the Twentieth Century, Cambridge, Cambridge University Press.

NOTAS

1 BERTRAND, R. \& CALAFAT, G. (2018). « La microhistoire globale : affaire(s) à suivre », Annales, Histoire, Sciences Sociales, 73 e année (1), 1-18. https://doi.org/10.3917/anna.731.0001. 